\title{
O Uso de Tecnologias Cívicas no Vale do Caí
}

\author{
Eduardo Luiz Gradischnig ${ }^{\dagger}$ \\ Instituto Federal do Rio Grande do \\ Sul - IFRS \\ Feliz, RS, Brasil \\ eduardoluizgradischnig@gmail.com
}

\author{
Vanessa Petró \\ Instituto Federal do Rio Grande do \\ Sul - IFRS \\ Feliz, RS, Brasil \\ vanessa.petro@feliz.ifrs.edu.br
}

\author{
Vinicius Hartmann Ferreira \\ Instituto Federal do Rio Grande do \\ Sul - IFRS \\ Feliz, RS, Brasil \\ vinicius.ferreira@feliz.ifrs.edu.br
}

\begin{abstract}
The Internet is one of the main ways of interaction, production and consumption of content. The active participation of individuals in this environment, disseminating ideas and defending or proposing political agendas, can be considered as a new form of social mobilization, especially in the current pandemic context in which social distance is recommended. Based on this, this article presents the results of a project that aimed to investigate and learn about popular participation in the administrative sphere through the Internet in the municipalities that make up the Vale do Caí region. To achieve this goal, through exploratory research and a qualitative approach, all available technologies were mapped for citizens to participate in the political life of the 20 municipalities that make up the region from the websites of their prefectures. The analysis of these technologies is essential to understand how the interaction between the government and the citizen occurs in the Vale do Caí region.
\end{abstract}

\section{PALAVRAS-CHAVE}

Tecnologia Cívica, Democracia, Participação Popular.

\section{INTRODUÇÃO}

O clássico conceito de cidadania sintetizado por [1] afirma que ela é composta por três dimensões: os direitos civis, políticos e sociais. Os direitos civis são constituídos por elementos necessários à liberdade individual, incluindo o direito à justiça, que reúne a defesa de todos os direitos em termos de igualdade. Todos os elementos relativos a condições mínimas de bem-estar econômico, que possibilitem ter um padrão de vida de acordo com os modelos vigentes na sociedade e a possibilidade de participar da herança social estão ligados aos direitos sociais. Os direitos políticos congregam a possibilidade de participar do exercício do poder político.

Quando se trata dos direitos políticos há uma tendência cotidiana de resumi-los ao direito de votar, o qual muitos consideram como uma obrigação e refletem sobre a sua real validade nesses moldes. Entretanto, os direitos políticos são muito mais amplos e estão diretamente entrelaçados aos demais na constituição da cidadania.
Há um elemento central associado à cidadania que é o protagonismo do cidadão. Concebemos o cidadão como o centro, como aquele que acompanha, que reivindica, que dá cara para a cidadania. No entanto, sabemos que essa perspectiva se tornou quase um "dever ser" da cidadania. Na prática os cidadãos se apresentam, em geral, mais distantes do poder público, inclusive descrentes nas instituições políticas.

Partindo destas definições, este artigo apresenta os resultados de uma pesquisa que tem como foco investigar e conhecer como se dá a participação popular pela Internet nos municípios que compõem a região do Vale do Caí. Esta região situa-se no Rio Grande do Sul e é formada por 20 municípios predominantemente colonizados por açorianos, alemães e italianos.

\section{REFERENCIAL TEÓRICO}

Para [2], "a cidadania moderna, ou seja, a integração das pessoas no governo via participação política, na sociedade, via garantia de direitos individuais, e no patrimônio coletivo, via justiça social, continua sendo aspiração de quase todos os países, sobretudo dos que se colocam dentro da tradição ocidental”.

Historicamente, segundo [3], no caso brasileiro poderíamos encontrar uma explicação para esse comportamento que é o fato de não haver uma apropriação dos direitos expressos constitucionalmente, porque o estado nem sempre é capaz de cumpri-los, ou pelo desconhecimento que os cidadãos apresentam sobre a existência dos mesmos. Há um deslocamento no espaço ocupado pelos cidadãos na construção da cidadania, que Carvalho denomina como estadania, expressando uma relação clientelista entre os cidadãos e o Estado. Isso incorre no fato de que no Brasil, por exemplo, os direitos sociais foram constituídos em um período em que não havia direitos políticos e assim soaram como uma benesse do Estado, resultando no efeito de que os cidadãos esperam que o poder público faça e o faça sozinho. Isso reduz o protagonismo dos cidadãos.

No âmbito desse projeto abordamos a participação no poder público mediada pela Internet. Tratamos, portanto, de uma forma de manifestação da cidadania, que busca retomar o protagonismo do cidadão.

Portanto, para fazer essa análise, utilizamos conceitos abordados em [4], em que "define-se democracia digital a busca e o exercício da democracia usando mídias digitais na comunicação política online ou offline, caso em que são usadas como apoio. A democracia digital é basicamente o uso de TICs em diferentes 
mídias com o objetivo de fortalecer a democracia ou a participação cidadã na comunicação política". Isso significa que tecnologias cívicas não se limitam apenas à Internet, mas representam todas as formas de tecnologias da informação e comunicação, sendo a Internet a principal delas.

\section{METODOLOGIA}

Para alcançar o objetivo proposto foi realizada uma pesquisa caracterizada como exploratória e com abordagem qualitativa através de análise e classificação das funcionalidades encontradas no site de todas as prefeituras dos municípios do Vale do Caí a fim de mapear as tecnologias cívicas disponibilizadas.

Os critérios de análise para definir uma funcionalidade de um site como uma tecnologia cívica, e também classificar essa tecnologia como de Interação ou de Transparência, são os critérios representados na Figura 1.

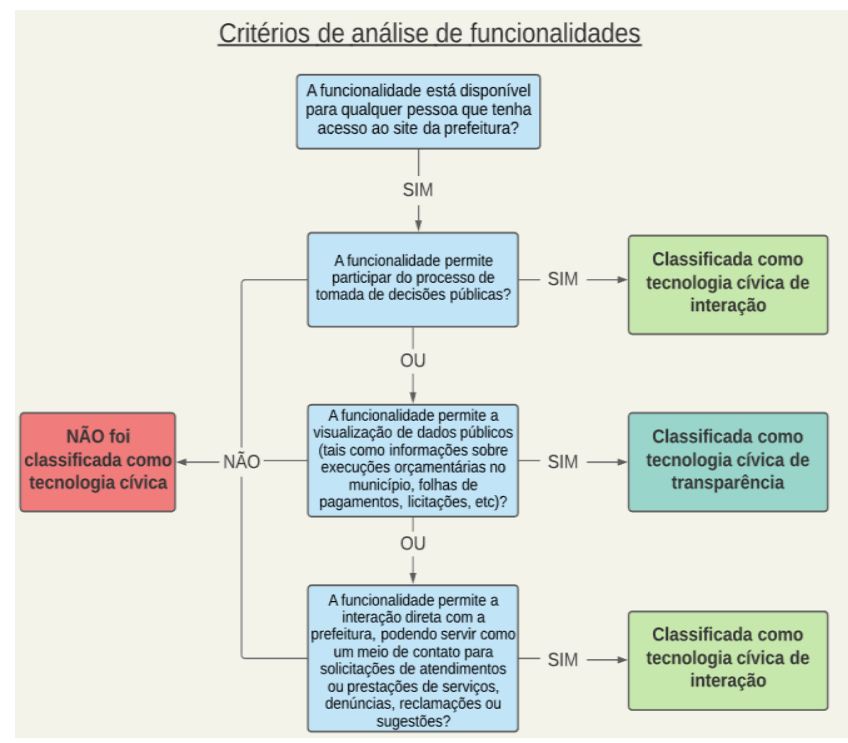

Figura 1: Critérios de análise para a classificação das funcionalidades dos sites.

A análise foi realizada a partir de critérios levantados por meio da literatura pertinente ao tema [5]. Junto com a análise dos sites um relatório foi elaborado com o objetivo de organizar os nomes e as funcionalidades das tecnologias cívicas encontradas, bem como suas classificações. A classificação foi uma ferramenta para agrupar tecnologias cívicas que possuíam características semelhantes, facilitando assim a análise dessas tecnologias.

As tecnologias foram classificadas como de Interação, quando permitem a interação entre o cidadão e o poder público, ou como de Transparência, quando divulgam dados de interesse público (Figura 1). É importante salientar que as tecnologias cívicas só foram classificadas em apenas um desses dois grupos, nunca em ambos.

\section{RESULTADOS E DISCUSSÕES}

O principal resultado que obtivemos, com a realização dos procedimentos metodológicos descritos, foi um relatório em que constam todas as tecnologias cívicas encontradas nos sites das vinte prefeituras da região do Vale do Caí.

Foram encontradas no total cento e quarenta e oito (148) tecnologias cívicas, das quais trinta e sete (37) foram classificadas como tecnologias cívicas de interação e cento e onze (111) como tecnologias cívicas de transparência (Figura 2).

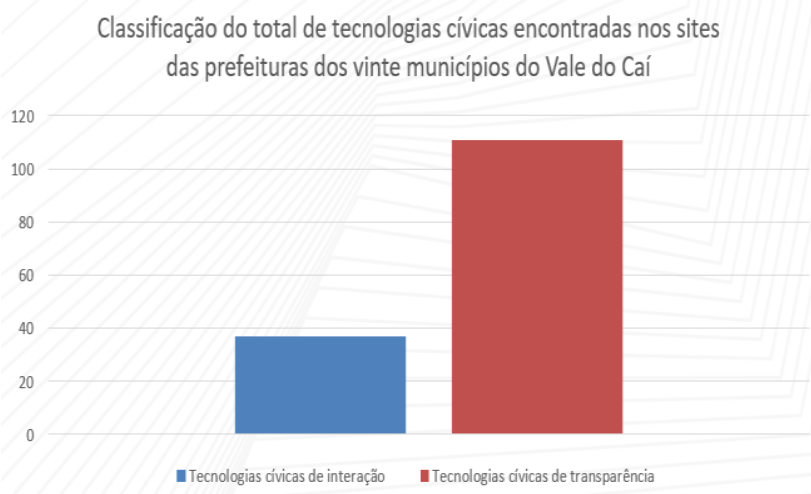

Figura 2: Gráfico com resultados do mapeamento dos sites das prefeituras.

Analisando a diferença do número de tecnologias cívicas de interação em relação com o número de tecnologias cívicas de transparência, percebe-se que a maioria das tecnologias encontradas não permitem a interação direta do cidadão com o poder público. E mais que isso, das cento e quarenta e oito (148) tecnologias cívicas encontradas no total, nenhuma delas concedia ao cidadão a funcionalidade de participar do processo de tomada de decisões públicas, critério este utilizado na análise das funcionalidades dos sites (Figura 1).

Portanto, a principal conclusão que podemos ter ao analisar o relatório é a de que, embora todas as cidades da região possuam um site disponível que auxilie na participação cidadã de seus moradores, nenhuma cidade possui uma tecnologia de participação direta na tomada de decisões públicas.

Ademais, é possível também fazer uma análise dessas tecnologias sobre o ponto de vista da segurança da informação, visto que alguns sites possuíam tecnologias que não estavam funcionando (e que não foram contabilizadas como tecnologias cívicas) corrompendo um dos pilares da segurança da informação - a disponibilidade. Esse fato pode corroborar ainda mais para uma sensação de insegurança por parte dos cidadãos que utilizam ou utilizariam essas tecnologias, podendo fazer com que as tecnologias que foram feitas para aproximar o poder público e o cidadão agora façam exatamente o contrário. 


\section{Computer on the Beach}

Além disso, com base na dificuldade de acesso a informações centralizadas e em língua portuguesa referentes a tecnologias cívicas, desenvolvemos um site com objetivo de facilitar o acesso a informações e exemplos relacionados a esse tema. Além dessas informações e exemplos, o site também apresenta como nosso projeto de pesquisa foi desenvolvido e os resultados do relatório, que são apresentados em diferentes tipos de gráficos. $\mathrm{O}$ site pode ser acessado por qualquer pessoa e seu endereço é "tecnocivic.feliz.ifrs.edu.br".

\section{CONSIDERAÇÕES FINAIS}

A proposta do projeto de pesquisa foi desenvolvida com o objetivo de buscar o fortalecimento da democracia, especialmente na região do Vale do Caí, região em que o Instituto Federal de Educação, Ciência e Tecnologia do Rio Grande do Sul Campus Feliz se encontra. Para alcançar tal objetivo, o relatório desenvolvido através dos sites das prefeituras da região e suas respectivas classificações foi essencial para que seja possível realizar uma análise mais detalhada sobre como ocorre a participação cidadã no meio digital na região do Vale do Caí.

Através do relatório percebemos que as áreas de tecnologia de informação e comunicação ainda não refletem a realidade da democracia praticada fisicamente, como por exemplo através do voto. E que mesmo não refletindo essa realidade, podem possuir alguns problemas relacionados à segurança.

A próxima etapa que se pretende realizar é a de entrevistas com os responsáveis pelas tecnologias cívicas a fim de compreender como os cidadãos as utilizam e identificar outras formas de participação cidadã, também pela tecnologia. Serão selecionados para entrevista os responsáveis pelas tecnologias cívicas dos cinco maiores municípios da região do Vale do Caí.

\section{REFERÊNCIAS}

[1] MARSHALL, T. H. Cidadania, classe social e status. Rio de Janeiro: Zahar, 1967.

[2] CARVALHO, J.M. Cidadania, estadania, apatia. Jornal do Brasil, Rio de Janeiro, p.8, 24 jun. 2001.

[3] CARVALHO, J.M. Cidadania no Brasil: o longo caminho. 9. ed. Rio de Janeiro: Civilização Brasileira, 2008.

[4] PALAZZO, Luiz; VANZIN, Tarcísio. Cibersociedade e novas tecnologias. Erechim: Deviant, 2018.

[5] DEPINÉ, Ágatha; VECHI, Sicilia; KIANE, Rayse; PERASSI, Richard. CAPÍTULO X: ágoras digitais: estudo comparado entre aplicativos para participação cidadã. In: VANZIN, Tarcisio; PALAZZO, Luiz Antonio Moro (org.). CIBERSOCIEDADE E NOVAS TECNOLOGIAS. Erechim: Deviant, 2018. p. 181-204. 